\title{
Diffuse Intrinsic Pontine Glioma
}

National Cancer Institute

\section{Source}

National Cancer Institute. Diffuse Intrinsic Pontine Glioma. NCI Thesaurus. Code C94764.

A neurog lial tumor that arises from the middle portion of the brain stem. It usually affects children and has a poor prognosis. 